\title{
The utility of Prostar XL percutaneous vascular closure device after stent-graft implantation for infrarenal abdominal aortic aneurysms
}

\author{
Marek Iłżecki', Marek Majewski', Piotr Terlecki', Stanisław Przywara', \\ Wojciech Rogala', Janusz Rybak', Tomasz Zubilewicz' \\ 'Department of Vascular Surgery and Angiology UM Lublin, Poland \\ ${ }^{2}$ Service de Chirurgie Vascularie Hopital Henri Mondor, Creteil, France
}

\begin{abstract}
Introduction. Over time, endovascular techniques of abdominal aortic aneurysm repair became the principal methods of treatment of this potentially fatal disease. Currently, endovascular aneurysm repair (EVAR) constitutes an effective alternative to open surgery, also in cases of aneurysm rupture. Low degree of invasiveness is the main advantage of this method. Introduction of a system enabling percutaneous stent-graft implantation appears to be the next step in the development of endovascular AAA surgery.

Aim of the study is to evaluate the Prostar $X L^{\circledR}$ closure device with regard to clinical effectiveness, safety, cost-effectiveness.

Material and methods. The study included 100 patients (from January 2013 to December 20 I5) subject to endovascular abdominal aortic aneurysm repair in the infrarenal region of the aorta with the application of the Prostar $X I^{\circledast}$ closure device. Most patients were operated under epidural anaesthesia. Local anaesthesia ( I\% Lidocaine) was used in 36 patients due to comorbidities. A possible application of the closure system depended on a preoperative assessment of common femoral arteries using ultrasonography. Presence of atherosclerotic plaque on the anterior wall of the vessel disqualified the patient from percutaneous endovascular aneurysm repair (PEVAR). The main part of the procedure consisted of stent-graft implantation into the abdominal aortic aneurysm. In the final stage, puncture site on the anterior wall of common femoral arteries was closed using previously placed sutures of the Prostar XL system. The wound in the inguinal region was closed with a skin suture. Results. The analysis of obtained results demonstrated significantly shorter mean hospitalization times in patients treated with PEVAR compared to EVAR. Low rates and types of observed complications in the study group (PEVAR) compared to the control group (EVAR) are strongly in favour the percutaneous technique (PEVAR) of endovascular aortic abdominal aneurysm repair in the infrarenal region of the aorta, confirming its minimally invasive character.
\end{abstract}

Key words: PEVAR, prostar XL, AAA

Acta Angiol 2018; 24, 3: 74-79

\section{Introduction}

Over time, the endovascular technique of abdominal aortic aneurysm repair developed by Volodos in the 1980s and Parodi in the 1990s became a principal method of treatment of this potentially fatal disease [I]. Currently, endovascular procedure (EVAR) became an effective alternative to open surgery, also in cases of ruptured aneurysms [2-4]. Low degree of invasiveness, which is the basic safety requirement for

Address for correspondence: Wojciech Rogala Department of Vascular Surgery and Angiology UM Lublin, ul. Stanisława Staszica I6, 20-400 Lublin, Poland, e-mail: wojtekrogala89@gmail.com 
the procedure in patients with cardiovascular comorbidities, constitutes the main advantage of this method. Implementation of a system enabling percutaneous stent-graft implantation seems to be the next step in the development of endovascular surgery. Inadequate experience of the operating surgeon and lack of properly equipped hybrid cath lab are the natural limitations of endovascular procedures, EVAR in particular. Rapidly growing number of procedures performed using EVAR technique opened a new chapter in the history of vascular surgery. It was also an inspiration for further progress and simplification of procedures, increasing their accessibility. Reduced hospitalization time, lower costs of treatment and, above all, the significantly less invasive character of this procedure are strong enough reasons for routine use of EVAR together with Prostar $\mathrm{XL}$ system.

Authors of this study aimed to evaluate the Prostar $\mathrm{XL}^{\circledR}$ system based on 100 cases of percutaneous AAA repair with regard to the following categories: technical success - expressed as the proportion of conversions to classic closure of anterior wall of the common femoral artery due to suture leakage to the total number of performed procedures, safety of the closure system - defined as the number and quality of complications associated with the use of Prostar XL and ability to treat them in a fast and effective manner, as well as cost-effectiveness - defined as hospitalization time and total cost of the procedure. In order to validate the study, we compared obtained results to a control group of equal size, consisting of 100 patients undergoing EVAR with surgical exposure of femoral arteries.

\section{Material and methods}

There were 432 patients treated surgically for an abdominal aortic aneurysm at our Department between January 2013 and December 2015. The study included 100 patients treated with percutaneous stent-graft implantation using the Prostar $\mathrm{XL}^{\circledR}$ system. Each patient was referred for endovascular treatment of AAA based on angio-CT imaging. Patients also underwent an ultrasound examination of the common femoral arteries. Authors of this study support the notion that computed tomography angiography, which is the basis of qualification to endovascular AAA repair, should also involve the evaluation of common femoral arteries. Presence of atherosclerotic plaque on the anterior wall of the vessel (from the level of inguinal ligament to the bifurcation) in both $\mathrm{CT}$ and Doppler ultrasound ruled out possible application of the Prostar $X L^{\circledR}$ system. Figure $I$ and 2 show an ultrasound picture of a vessel that precludes the potential use of the Prostar XL closure system. However, tortuous

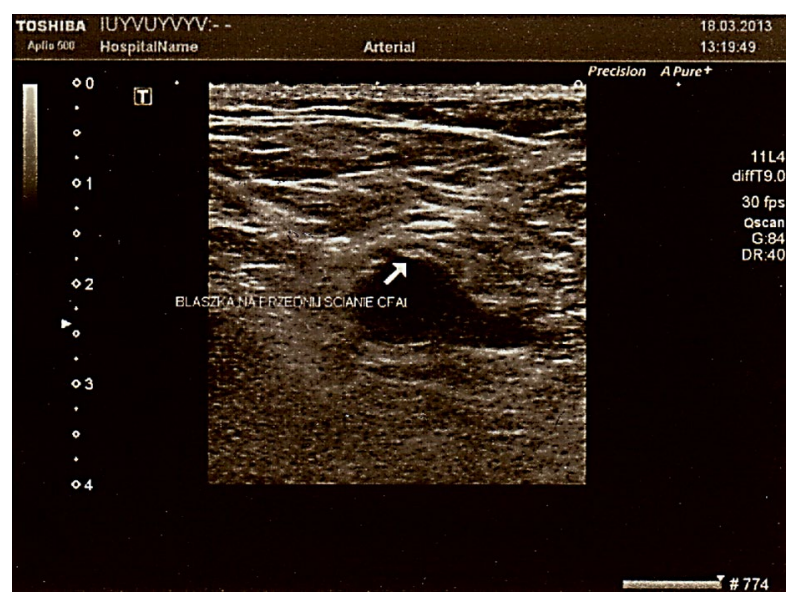

Figure I. Atherosclerotic plaque at the anterior wall of common femoral artery

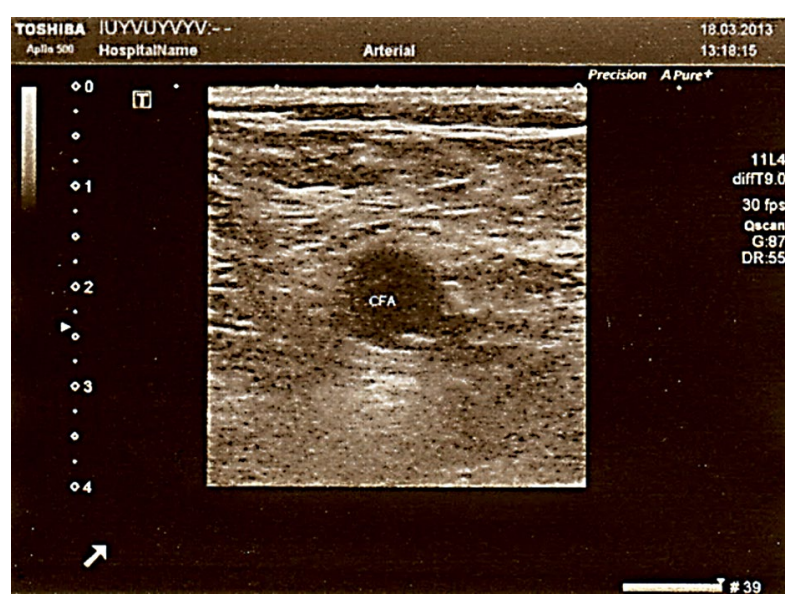

Figure 2. Anterior wall of common femoral artery without atherosclerotic lesions

inguinal arteries did not constitute contraindications to Prostar XL. The procedure was performed under conditions typical for any other endovascular surgery, using standard disinfecting agents and usual draping of the surgical field. Epidural anesthesia was used during the procedure. Local anesthesia using 1\% Lidocaine (about $15 \mathrm{~mL}$ for each side) was used in about $3 \mathrm{I}$ cases due to comorbidities. Among the entire group of 162 subjects, $4 \mathrm{I}$ patients underwent urgent surgery for a symptomatic abdominal aortic aneurysm. Remaining patients were treated with elective procedures. Table I presents the numerical distribution of the study group. Control group consisted of 100 patients treated with stent-graft implantation to AAA through classic surgical exposure of common femoral arteries. Demographic characteristics of both groups are presented in Table I. 
Table I. Comparison of study group (PEVAR) and control group (EVAR) hospitalization times

\begin{tabular}{|c|c|c|c|c|c|c|c|c|}
\hline $\begin{array}{l}\text { Patient } \\
\text { group }\end{array}$ & Sex & No. & $\begin{array}{l}\text { Mean } \\
\text { age }\end{array}$ & $\begin{array}{c}\text { Mean hospitalization } \\
\text { time } \\
K / M \text { days }\end{array}$ & $\begin{array}{c}\text { Mean hospitalization } \\
\text { time/total } \\
\text { (days) }\end{array}$ & $\begin{array}{l}\text { Difference } \\
\text { Days } / \% \\
\text { (M) }\end{array}$ & $\begin{array}{l}\text { Difference } \\
\text { Days/\% } \\
\text { (K) }\end{array}$ & $\begin{array}{c}\text { Difference } \\
\text { Total } \\
\text { Days } / \%\end{array}$ \\
\hline \multirow[t]{2}{*}{$\begin{array}{l}\text { Study } \\
\text { group }\end{array}$} & $\mathbf{F}$ & 22 & 74.77 & 2.36 & 2.45 & $\begin{array}{c}2.38 \\
\mathrm{~d} / 49.07 \%\end{array}$ & $\begin{array}{c}2.59 \\
\text { d/53.40\% }\end{array}$ & $\begin{array}{c}2.42 \\
\mathrm{~d} / 49.69 \%\end{array}$ \\
\hline & $M$ & 78 & 75.47 & 2.47 & & & & \\
\hline \multirow{2}{*}{$\begin{array}{l}\text { Control } \\
\text { group }\end{array}$} & $\mathbf{F}$ & 20 & 71.40 & 4.95 & 4.87 & & & \\
\hline & $M$ & 80 & 72.70 & 4.85 & & & & \\
\hline
\end{tabular}

Under ultrasound guidance, the anterior wall of the femoral artery was punctured with an I8G needle at a $45^{\circ}$ angle to the long axis of the vessel (common femoral artery). The system was introduced along with a I80-cm hydrophilic Terumo ${ }^{\circledR}$ guidewire. Tissues were separated to create a channel to the anterior arterial wall, enabling uninterrupted tightening of sutures at the final stage of the procedure. Proper positioning of the effector part of the system (in the arterial lumen) was indicated by retrograde blood flow from a control cannula running from the top of the effector part of the system to its "handle". In the next step, sutures were placed according to the method designed for the Prostar $X L^{\circledR}$ system. The contralateral femoral procedure was prepared in an analogous manner. Each patient routinely received 5 thousand units of unfractionated heparin intraoperatively. The main part of the procedure involved implantation of a stent-graft into the abdominal aortic aneurysm using a surgical technique recommended for an individual type of endograft. At the final stage, the opening in the anterior wall of the common femoral artery (formed due to the introduction of the stent-graft system) was closed by tightening of the previously placed sutures using a "Knot Pusher" included in a standard Prostar $\mathrm{XL}^{\circledR}$ set. Tissue channel (about $10 \mathrm{~mm}$ in diameter) formed, as previously mentioned, by incising the skin in the axis of the system and separating tissues around the cannula, ran from skin surface down to the wall of the artery, enabling uninterrupted placement of sutures in the desired location (anterior wall of common femoral artery). The procedure was finished with the placement of single skin sutures at the puncture site in the inguinal region bilaterally (Fig. 3). Among the aforementioned group of 31 patients, the puncture site was anesthetized on both sides in the first stage of the procedure and the remaining steps of PEVAR were conducted in a manner analogous to that described above. A protocol of follow-up visits was established for the study group: 4 weeks, 12 weeks, 6 months, and 12 months after surgery. Ultrasound examination of the puncture site (inguinal regions bilaterally), common femoral veins, stent-graft positioning,

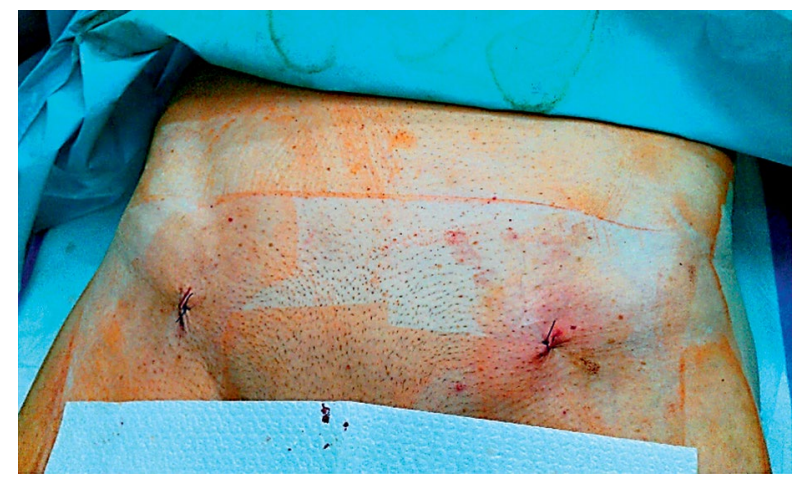

Figure 3. Cosmetic effect of the PEVAR procedure using Prostar XL

blood flow through the main body of the stent-graft as well as through its inguinal extensions was performed in each patient four weeks after the procedure. Similar assessments were performed during follow-up visits 12 weeks and 6 months after the procedure. During the I-year follow-up visit patients underwent angio-CT examination, enabling detection of a possible leak. Each patient received double antiplatelet therapy postoperatively, which was reduced to ASA only starting from the $6^{\text {th }}$ month after the procedure.

\section{Analysis of results}

The analysis included 100 patients treated with percutaneous endovascular aneurysm repair (PEVAR) method using a Prostar $X L^{\circledR}$ closure system. Obtained numerical results were subject to a comparative analysis between the study group and the control group comprising of 100 patients treated with standard EVAR technique with regard to three categories: I) technical success of Prostar XL closure system - was obtained in 95 cases from the study group, amounting to $95 \%$ of subjects. Among 6 complications, which amounted to $3.7 \%$ of the study group, bleeding at the site of Prostar $\mathrm{XL}$ suture placement was observed in 4 cases and in 2 cases pseudoaneurysms were diagnosed after three and six months of follow-up. In the control group ( 100 
patients) complications were noted in 5 cases, which amounted to $5 \%$ of the control group. Complications included two cases of lymphorrhea at the surgical site, two cases of wound infection, and one case of hematoma at the surgical site. Numerical distributions of observed complications are presented in Table 2. 2) safety of the Prostar $X L$ closure system was assessed in relation to the types of observed complications. As mentioned before, pseudoaneurysm in the inguinal region was diagnosed in 2 cases. The smaller one $(21 \times$ $32 \mathrm{~mm}$ ) was treated successfully with Thrombin $400^{\circledR}$ injection under ultrasound guidance (Figs I, 2), while the larger one was removed surgically. In four cases bleeding at the site of Prostar XL, suture placement was managed intraoperatively by converting to open procedure - a common femoral artery was exposed at the puncture site and the opening in the wall was closed with Prolene 5-0 continuous suture. Such a conduct is a part of routine training for a vascular surgeon and does not pose a particular challenge. 3) Cost-effectiveness was assessed by comparing the duration of hospitalization and total cost of treatment between study and control groups. Comparative analysis demonstrated that hospitalization time was significantly shorter after PEVAR compared to EVAR and amounted to 2.45 days. Table I. compares hospitalization times in the compared patient groups.

\section{Discussion}

Percutaneous implantation of a stent-graft into abdominal aortic aneurysm appears to be a natural step in the development of minimally invasive endovascular techniques [5, 6]. It is particularly important for patients with multiple comorbidities, especially cardiological, in whom a standard EVAR procedure performed under epidural anaesthesia constitutes an elevated surgical risk $[4,7,8]$. Literature underscores the importance of proper classification of patients for PEVAR procedure, which determines the technical success of the surgery. Presence of severe atherosclerotic lesions involving common femoral artery is a fundamental contraindication for percutaneous stent-graft implantation [9] point to the prognostic value of atherosclerotic plaque at the anterior wall of CFA, but do not postulate it as an absolute contraindication to PEVAR on that basis. In our opinion, identification of atherosclerotic lesions in this location at the CFA wall constitutes a contraindication to PEVAR. Angio-CT examination (encompassing common femoral arteries) is somewhat helpful in the qualification to the percutaneous procedure, enabling proper preoperative assessment of the anatomy of the aorta, inguinal and femoral arteries [10]. Obese patients $(\mathrm{BMI}>30)$ constitute a special group of patients with a particularly high surgical risk, particularly with respect

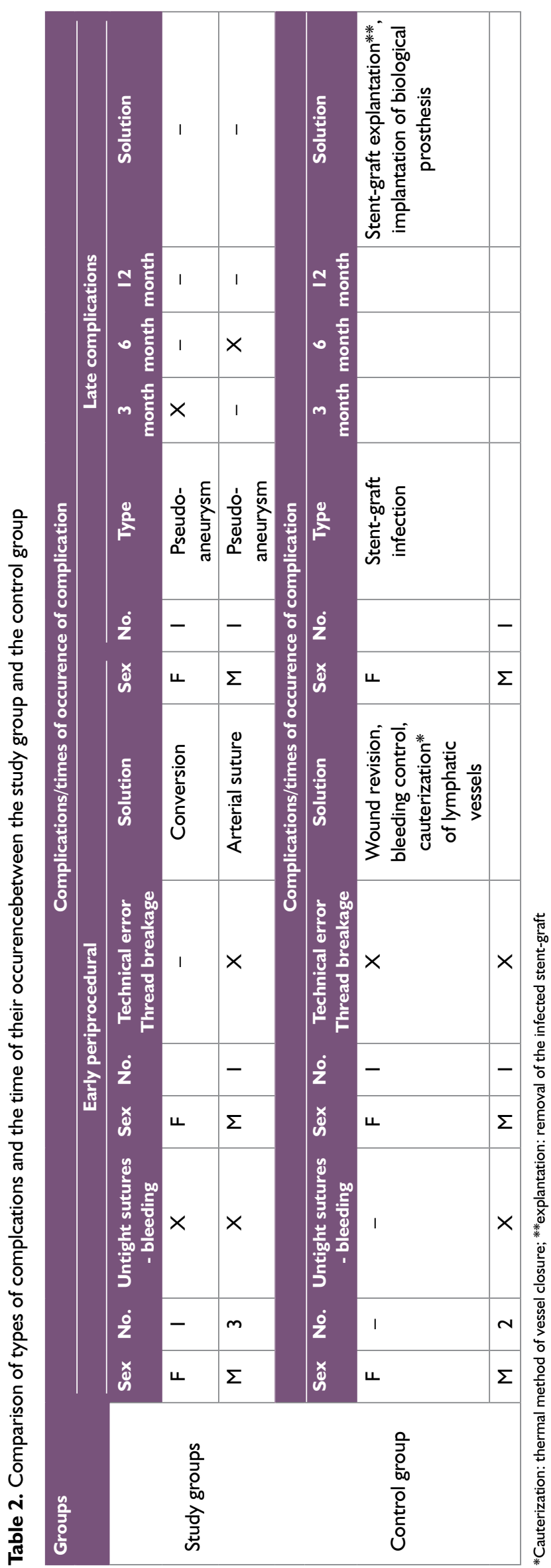


to open procedures [ $\mathrm{I} \mathrm{I}]$. A decision regarding the choice of proper surgical technique should take into consideration PEVAR as first-line treatment of AAA repair being least burdensome. We share this belief. Among our study group, 12 patients were obese, including 9 with BMI between 30 and $40 \mathrm{~kg} / \mathrm{m}^{2}$ and 3 with BMl over $40 \mathrm{~kg} / \mathrm{m}^{2}$. In this group PEVAR procedures were complication-free, supporting the rationale for qualifying obese patients to the percutaneous procedure. The problem of qualifying patients with $\mathrm{BMI}$ over 30 is often a matter of discussion in numerous reports, wherein particular emphasis is put on the value of minimally invasive procedures, such as PEVAR [3]. Complications associated with the use of Prostar XL closure systems observed in this study are partly justified by the relatively limited experience of the operating surgeon as well as improper patient qualification to the procedure. In a retrospective analysis of 238 I cases of percutaneous stent-graft implantation to AAA, Pratesi G, Barbante underscore the importance of proper training, which requires at least 50 PEVAR procedures performed independently [8, I2]. Presumably, any minimally invasive procedure is meant for patients with a particularly high risk of periprocedural complications due to multiple comorbidities, especially cardiological [13]. As previously mentioned in the paragraph describing the study group, only local anesthesia could be used in 31 of 100 patients. The procedure itself as well as the postoperative period was unremarkable, which strengthens our conviction that local analgesia could be used in patients with other comorbidities that increase the risk of complications. Similar conclusions may be found in numerous publications concerning the choice of proper anesthesia for severely ill patients referred for EVAR [14]. There are some doubts with regard to the quality of intraoperative imaging, especially at critical moments when precise stent expansion is a priority (stent-graft positioning), in the presence of unintended patient moves [15]. Our experiences do not corroborate the above-mentioned concerns.

\section{CONCLUSIONS}

Based on the analysis of our results, we concluded as follows:

I. The use of the Prostar XL closure system for endovascular AAA repair appears to be rational and highly beneficial.

2. The types of observed complications allowing for simple intraoperative management point to a high degree of safety.

3. Minimal invasiveness of the procedure and possible use of local anaesthesia enable the use of this method even in patients with significant cardiological comorbidities.

\section{Conflict of interest}

None.

\section{References:}

I. Parodi JC, Palmaz JC, Barone HD. Transfemoral intraluminal graft implantation for abdominal aortic aneurysms. Ann Vasc Surg. 199I; 5(6): 49I-499, doi: 10.1007/BF0201527I, indexed in Pubmed: 1837729.

2. Li Y, Li Z, Wang S, et al. Endovascular versus Open Surgery Repair of Ruptured Abdominal Aortic Aneurysms in Hemodynamically Unstable Patients: Literature Review and Meta-Analysis. Ann Vasc Surg. 2016; 32: 135-144, doi: 10.1016/j. avsg.2015.09.025, indexed in Pubmed: 26802303.

3. Peters AS, Hakimi M, Erhart P, et al. Current treatment strategies for ruptured abdominal aortic aneurysm. Langenbecks Arch Surg. 20I6; 40 I (3): 289-298, doi: I0.1007/s00423-016-1405-4, indexed in Pubmed: 27055854.

4. Portelli Tremont JN, Cha A, Dombrowsky V, et al. Endovascular repair for ruptured abdominal aortic aneurysms has improved outcomes surgical repair. Vasc Endovascular Surg. 2016, doi: I5385744 |6637442(Epub ahead of print).

5. Howell M, Villareal R, Krajcer Z. Percutaneous access and closure of femoral artery access sites associated with endoluminal repair of abdominal aortic aneurysms. J Endovasc Ther. 200I; 8(1): 68-74, doi: $10.1177 / 1526602801008001 / 2$, indexed in Pubmed: I I 220473.

6. Marlene Grenon S, Gagnon J, Hsiang YN, et al. Canadian experience with percutaneous endovascular aneurysm repair: short term outcomes. Can J Surg. 2009; 52: EI56-EI60.

7. Geisbüsch P, Katzen BT, Machado R, et al. Local anesthesia for endovascular repair of infrarenal aortic aneurysms. Eur J Vasc Endovasc Surg. 20I I; 42(4): 467-473, doi: 10. I016/j.ejvs. 20II.05.00।8.

8. Lee W, Brown M, Nelson P, et al. Total percutaneous access for endovascular aortic aneurysm repair ("Preclose" technique). Journal of Vascular Surgery. 2007; 45(6): 1095-II0I, doi: 10.1016/j.jvs.2007.01.050.

9. Nelson PR, Kracjer Z, Kansal N, et al. A multicenter, randomized, controlled trial of totally percutaneous access versus open femoral exposure for endovascular aortic aneurysm repair (the PEVAR trial). J Vasc Surg. 2014; 59(5): II8I-II93, doi: 10.1016/j.jvs.2013.10.101, indexed in Pubmed: 24440678.

10. Bakker EJ, van de Luijtgaarden KM, van Lier F, et al. General anaesthesia is associated with adverse cardiac outcome after endovascular aneurysm repair. Eur J Vasc Endovasc Surg. 2012; 44(2): I2I-125, doi: 10.10 |6/j.ejvs.20 I2.04.028, indexed in Pubmed: 22626989.

II. Chakfé N, Georg Y. Commentary on ,Predictors of Failure of Closure in Percutaneous EVAR Using the Prostar XL Percutaneous Vascular Surgery Device'. Eur J Vasc Endovasc Surg. 2015; 49(I): 50-5I, doi: 10.1016/j.ejvs.2014.12.005, indexed in Pubmed: 26013672.

12. Salomon du Mont L, Mauny F, Chrétien N, et al. Obesity is not an independent factor for adverse outcome after abdominal aortic aneurysm repair. Ann Vasc Surg. 2016; 33: 67-74, doi: 10.1016/j.avsg.2015.12.002, indexed in Pubmed: 26806243. 
13. Lee W, Brown M, Nelson P, et al. Midterm outcomes of femoral arteries after percutaneous endovascular aortic repair using the Preclose technique. Journal of Vascular Surgery. 2008; 47(5): 919-923, doi: 10.1016/j.jvs.2007.12.029.

14. Pratesi G, Barbante M, Pull R, et al. IPER Registry Collaborators. Italian percutaneous EVAR (IPER) registry: outcomes of 238 I percutaneous femoral accesess sites closure for aortic stentgraft. J Cardiovasc Surg(Torino). 2015; 56(6): 889-898.

15. Sadat U, Cooper DG, Gillard JH, et al. Impact of the type of anesthesia on outcome after elective endovascular aortic aneurysm repair: literature review. Vascular. 2008; 16(6): 340-345, doi: 10.2310/6670.2008.00053, indexed in Pubmed: 19344592. 